\title{
Partially Thrombosed Giant Posterior Inferior Cerebellar Artery Aneurysm Mimicking a Fourth Ventricular Tumour
}

\author{
Taofiq Sanusi", William Owiti, Juraj Schwab and Ashraf Abouharb
}

Department of Neurosurgery, Royal Victoria Hospital, Belfast, UK

*Corresponding author: Taofiq Sanusi, Department of Neurosurgery, Royal Victoria Hospital, Belfast, UK

\begin{abstract}
Background: Posterior circulation aneurysms are less common compared to the anterior circulation aneurysms Dissecting distal Posterior Inferior Cerebellar Artery, PICA, aneurysm is very uncommon. In this case report, we describe an adult who had distal PICA aneurysm in the $4^{\text {th }}$ ventricle which radiologically and symptomatically mimics a fourth ventricular mass lesion. Our aim is to add to the literature about rare but possible differential diagnosis of $4^{\text {th }}$ ventricular tumour.
\end{abstract}

Case presentation: A 43-year-old lady presented with a history of non-progressive headache, intermittent vomiting, heartburn and feeling like "food sticking in her throat". At the start of her symptoms, she was investigated for gastritis, she underwent CT chest, abdomen and pelvis, all of which were normal. She was treated with antiemetics and clinically improved. She represented ten (10) months later with recurrent of symptoms. On assessment in the emergency room, CT brain demonstrated a $4^{\text {th }}$ ventricular mass lesion which was initially thought to be neoplasia with ependymoma as top differential. MRI T2 weighted and FLAIR sequences suggested vascular lesion and angiographic study concluded a distal PICA dissecting aneurysm in the $4^{\text {th }}$ ventricle. She underwent endovascular treatment and made full recovery with resolution of symptoms.

Conclusions: PICA aneurysms are very rare; majority arises from the proximal three segments. Distal PICA segment aneurysms are even rarer, care must be taking in assessments and diagnosis of patients with a $4^{\text {th }}$ ventricular mass lesion as this could be a distal PICA dissecting aneurysm.

\section{Keywords}

Posterior inferior cerebellar aneurysm, Fourth ventricle, Distal PICA, Endovascular treatment

\section{Introduction}

The Posterior inferior cerebellar artery is one of the three main arterial supply of the cerebellum. It is the largest branch of the vertebral artery. It arises from the V4 (intradural) segment of the vertebral artery in about $90 \%$ of subjects. Extradural origin accounts for about $5-10 \%$.

PICA aneurysms are rare, they constitute only about $0.5-2 \%$ of intracranial aneurysms of which majority arises from PICA-Vertebral artery junction [1]. PICA aneurysms are usually smaller than $12 \mathrm{~mm}$, however, there is high propensity for the development of giant aneurysms [2].

PICA aneurysms can be accompanied by arteriovenous malformations in very rare cases. In such cases life-threatening cerebellar haemorrhage is a common presenting feature noted [2]. Haemodynamic changes due to the AVM are thought to be the factor responsible for the development of these aneurysms [2].

Distal PICA aneurysms are extremely rare and account for $0.3 \%$ of all PICA aneurysms [2].

Giant aneurysms are defined as aneurysms that have a maximum diameter greater than $25 \mathrm{~mm}$. Regardless of location, this class of aneurysms are difficult to treat. They have a higher risk of rupture and surgical/ endovascular treatment related morbidities and (or) mortalities. PICA aneurysms are generally treated by surgical clip ligation or endovascular embolization [3,4].

\section{Case Report}

We present a 43-year-old woman with a one-year

Citation: Sanusi T, Owiti W, Schwab J, Abouharb A (2021) Partially Thrombosed Giant Posterior Inferior Cerebellar Artery Aneurysm Mimicking a Fourth Ventricular Tumour. Neurosurg Cases Rev 4:071. doi.org/10.23937/2643-4474/1710071

Accepted: June 22, 2021; Published: June 24, 2021

Copyright: (C) 2021 Sanusi T, et al. This is an open-access article distributed under the terms of the Creative Commons Attribution License, which permits unrestricted use, distribution, and reproduction in any medium, provided the original author and source are credited. 
history of mild non progressive headache, vertigo, dizziness, intermittent vomiting and heartburn. She also had feeling of "food stuck in her throat". Her blood panels were unremarkable, she had CT chest, abdomen and pelvis which were unremarkable. She was treated with antiemetics and symptoms improved. She was discharged from a peripheral hospital.

She represented after about ten (10) months with intermittent dull occipital headache, vertigo and dizziness. Initially managed medically as suspected migraine, but due to symptoms being refractory to medical management, she was sent by her general practitioner to her local hospital for a head CT scan to rule-out space occupying lesion. At the emergency

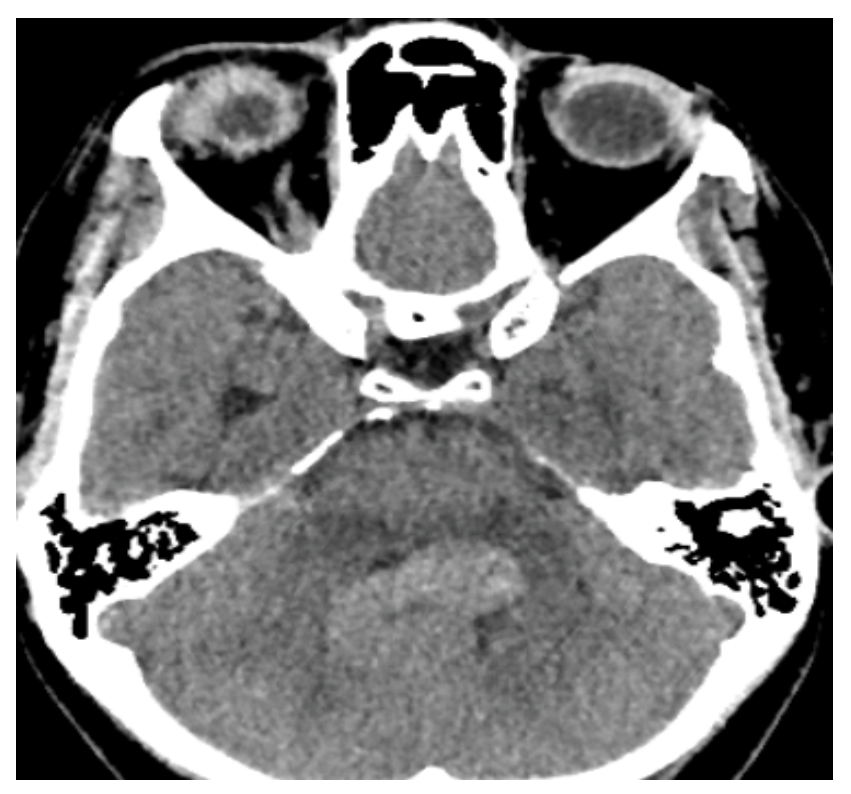

Figure 1: Non-contrast CT brain showing $4^{\text {th }}$ Ventricular mass lesion. room, she was found to have a left lateral nystagmus. Vertigo symptoms were present but Dix-Hallpike test was negative. She had no symptoms of viral infection; no recollection of trauma and her ENT review was normal. She did not have long-tract signs and no other lower cranial nerve palsies.

She had a medical history of depression and psoriasis.

Due to her symptomatology, a plain brain CT scan was performed. This revealed a hyperdense mass lesion in the fourth ventricle, which measures $32 \times 28 \mathrm{~mm}$ with some degree of obstructive hydrocephalus. CT with contrast revealed an avidly enhancing mass lesion filling the fourth ventricle (Figure 1).

The lesion was initially thought to be a $4^{\text {th }}$ ventricular tumour with ependymoma as top radiological differential. She was then transferred to our unit for further evaluation and management.

On arrival to our unit, we performed MRI sequences which include T2 weighted, susceptibility weighted, and T1 volume pre-and post-contrast and 3-D time-offlight MRA. These showed a serpiginous lesion within the fourth ventricle that exhibited a flow void on T2weighted imaging and appears to arise from terminal left posterior inferior cerebellar artery (Figure 2 and Figure 3).

The spine MRI did not reveal any significant abnormalities.

Patient had Digital Subtraction Angiogram, DSA, which showed a large multi-saccular aneurysm like a "petal leaf" arising distally from the left PICA which feeds into an elongated fusiform aneurysmal component (Figure 3 and Figure 4).

After consultation between the neurosurgical and

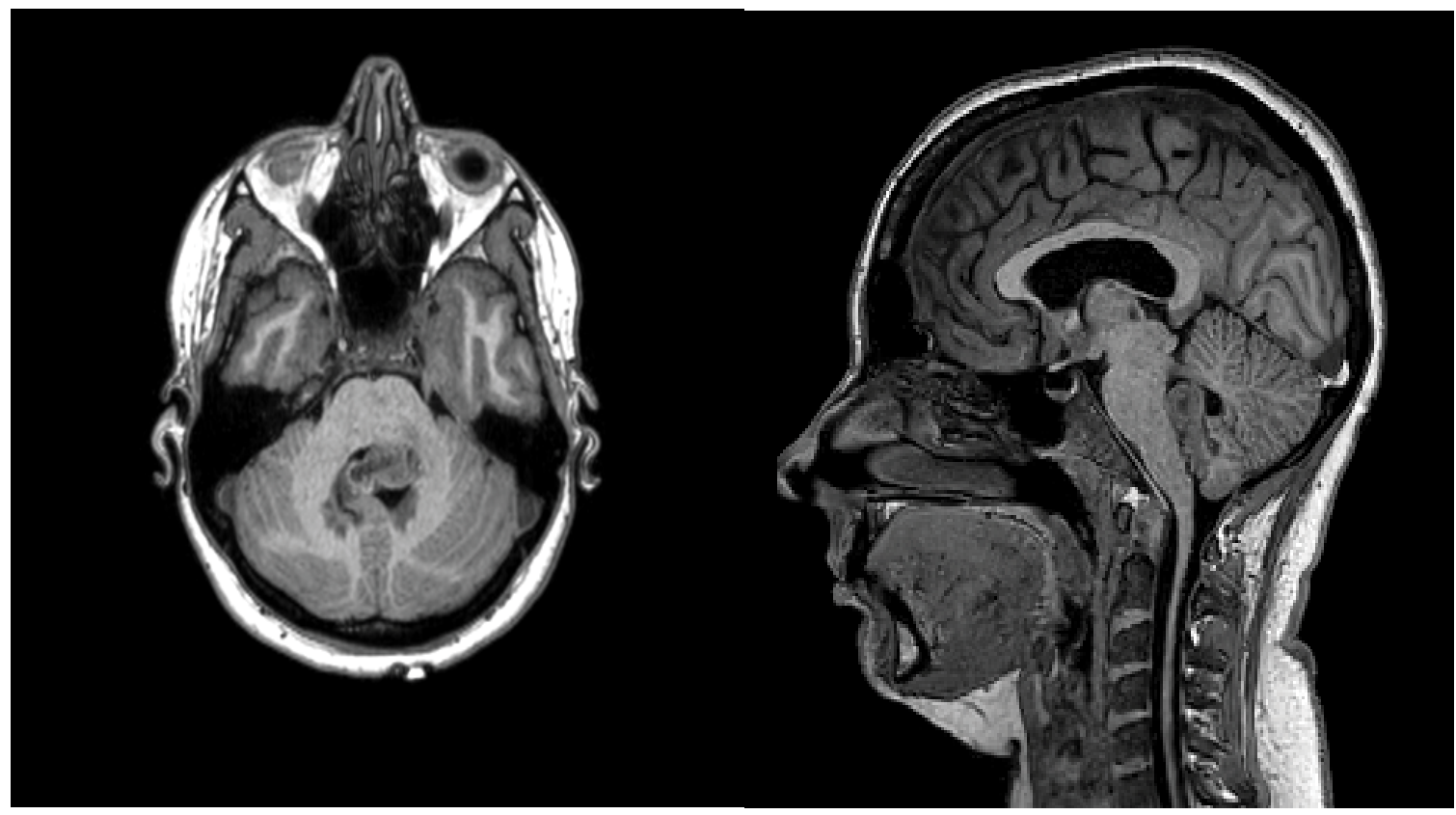

Figure 2: MRI T1- pre-contrast axial and sagittal showing the mixed intensity $4^{\text {th }}$ Ventricular tumour. 


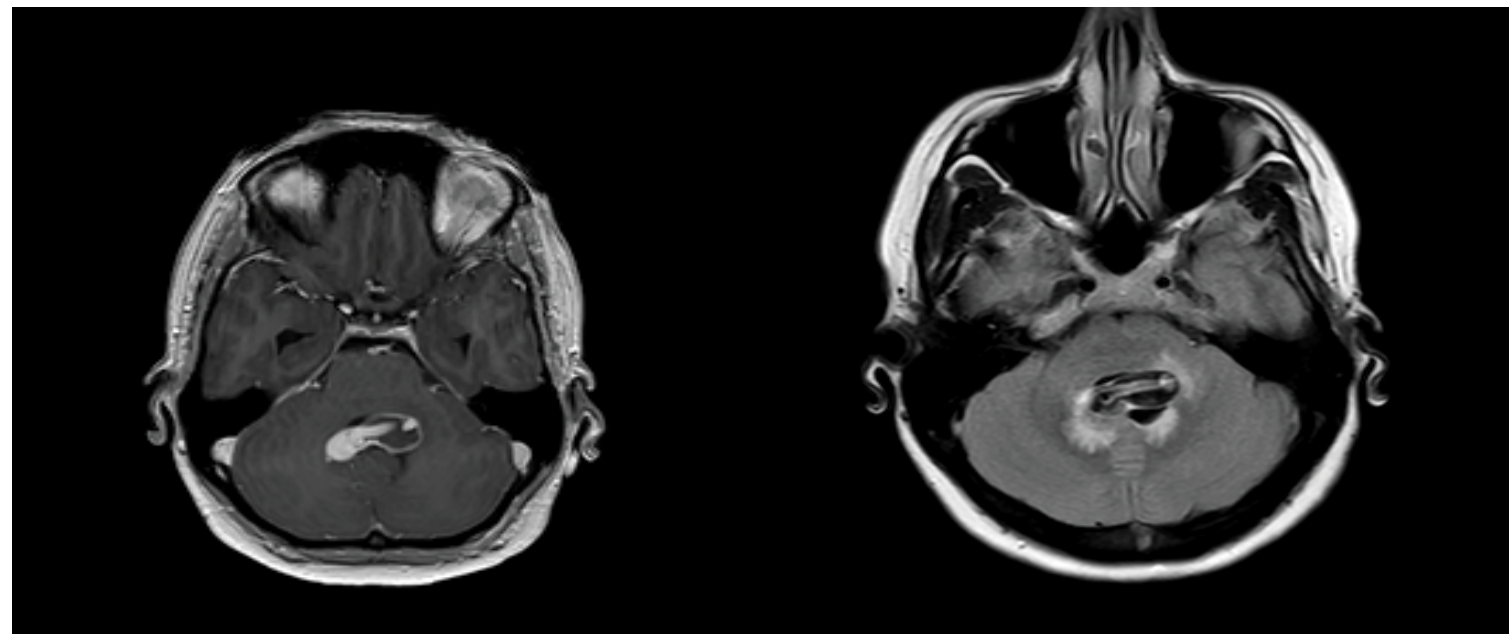

Figure 3: Post-contrast and FLAIR sequences demonstrate the $4^{\text {th }}$ ventricular lesion with flow void.

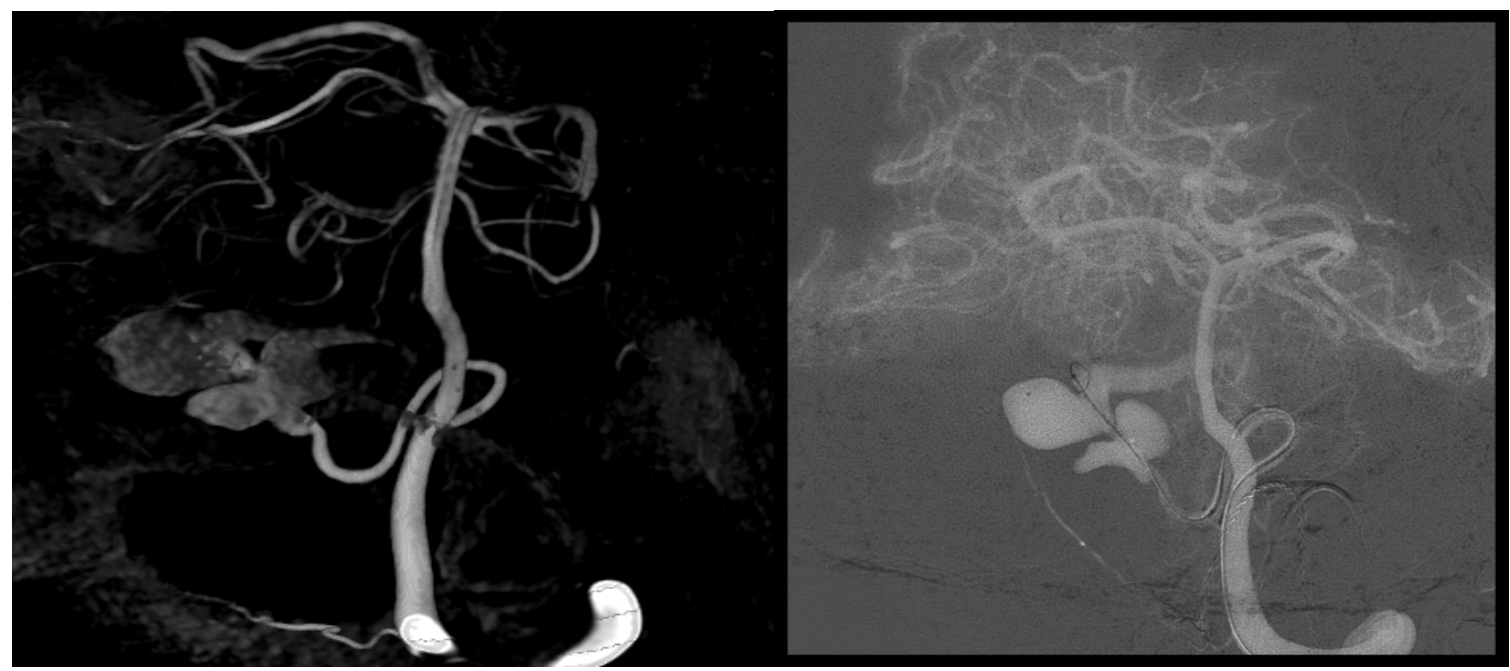

Figure 4: Angiographic study of the PICA aneurysm. Peri-operative angiogram of the $4^{\text {th }}$ Ventricular dissecting PICA aneurysm.

interventional neuroradiology teams, endovascular embolization of the dissecting distal PICA aneurysm favoured. A balloon test occlusion across the origin of the left PICA was carried out. This demonstrates satisfactory collateralisation to the distal right PICA territory.

Occlusion of the dissecting aneurysm and the terminal PICA was achieved with detachable coils, and no retrograde filling of aneurysm was demonstrated after the coiling, hence a satisfactory coil embolization of the distal PICA dissecting aneurysm was achieved.

The patient was transferred to ICU for observation for 24 hours and discharged a few days later no new neurology. Follow up MRA scans showed complete occlusion of lesion. Her left abducens nerve palsy was followed up by the orthoptics and in our last review, this is improving.

\section{Discussion}

The PICA artery originates usually from the vertebral artery at an average distance of $16-17 \mathrm{~mm}$ proximal to the vertebrobasilar junction [5]. In a study of fifty (50) cerebellar hemispheres from twenty-five (25) cadavers, Rhoton, et al. examined the PICA and described its course. The PICA was divided into five segments: (1) Anterior medullary segment in front of the medulla (2) Lateral medullary segment courses beside the medulla and extends to the origin of the glossopharyngeal, vagal, and accessory nerves; (3) Tonsillomedullary segment courses around the caudal half of the cerebellar tonsil; (4) Telovelotonsillar segment courses in the cleft between the tela choroidea and inferior medullary velum rostrally and the superior pole of the cerebellar tonsil caudally; (5) Cortical segment was distributed to the cerebellar surface (Figure 5) [5,6].

Aneurysms of the posterior inferior cerebellar artery (PICA) comprise $0.5-2 \%$ of all intracranial aneurysms $[7,8]$. The distal PICA aneurysms referred to those arising from the $4^{\text {th }}$ and $5^{\text {th }}$ segments.

A series by Park, et al. of 368 PICA aneurysms lists only 5 cases of distal PICA aneurysms [9]. 


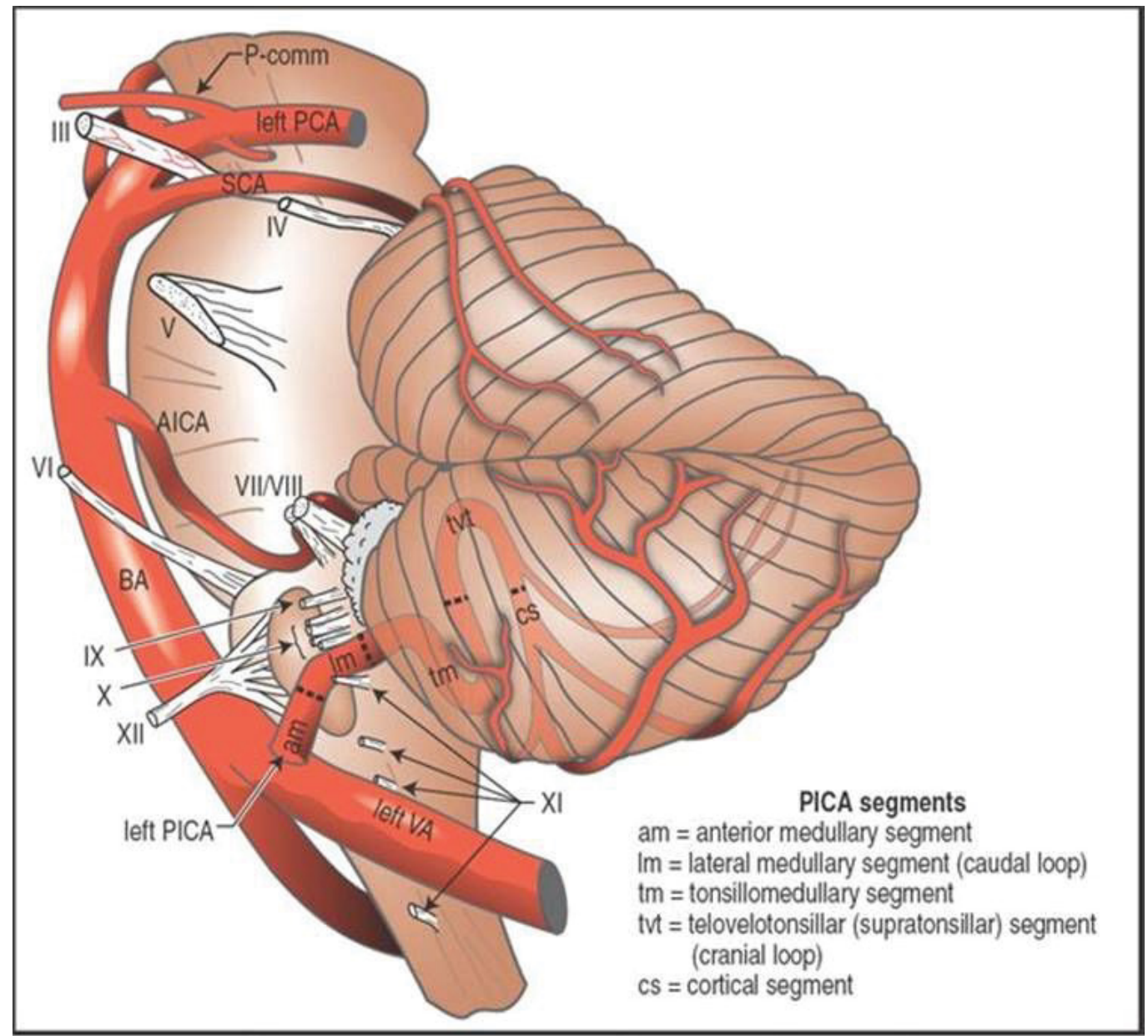

Figure 5: Image modified from: Handbook of neurosurgery Mark S Greenberg $8^{\text {th }}$ edition [6].

Most commonly, PICA aneurysms arise from lateral medullary segment followed by tonsillomedullary segment as seen in a large series of Tokimura, et al. [10].

Intracranial aneurysms typically arise at arterial bifurcations, however distal PICA aneurysms arise predominantly from the arterial side wall of the telovelotonsillar segment [11].

The mechanism of development of distal PICA aneurysm is poorly understood, however, a widely recognised mechanism proposed that increased hemodynamic wall shear stress is induced by the sharp hairpin curvature of the cranial loop that characterises this segment leading to formation of these aneurysms $[10,12]$.

Giant aneurysm in the $4^{\text {th }}$ ventricle might be misdiagnosed as tumours of posterior fossa due to similar clinical presentations and imaging features which are often indistinct as in our case report. Operating on a dissecting PICA aneurysm mimicking a tumour could be dangerous, hence adequate image modalities is of essential to make appropriate diagnosis.

Prompt diagnosis and treatment of these aneurysms is also important as they have higher rates of rupture [13].

Several tumours are typically considered as differen- tial diagnosis of the $4^{\text {th }}$ ventricle. These include Ependymomas, Subependymoma, Pilocytic Astrocytoma, Medulloblastomas, A typical Teratoid Rhabdoid Tumours (ATRT), PNET, Choroid Plexus Papilloma/Carcinomas and Glioblastoma.

In the case of our patient, our initial thought was ependymoma as the most likely radiological diagnosis. Ependymomas are typically well delineated and do arise from the floor of the fourth ventricle as opposed to medulloblastomas that do arise from the roof of the fourth ventricle and lobal in adults. Ependymomas are typically mixed intensity relative to brain parenchyma on T1W1 and hyper intense on T2/FLAIR. Typically, these tumours have areas of avid homogenous contrast enhancement that are intermixed with foci of minimal or no enhancement.

A large partially thrombosed giant aneurysm may mimic the radiological appearance of a tumour, hence high index of suspicion must be exercised and vascular lesion should be included in the differential diagnosis.

Our patient's imaging demonstrated a lesion filling the entire fourth ventricle with a flow void on $\mathrm{T} 2$ weighted imaging. There was increased signal on 3-D time of flight angiography. The presence of a flow void in the $\mathrm{T} 2$ weighted imaging was a unique feature that 
allowed us to suspect an aneurysm in imaging that would have otherwise been diagnosed as a tumour.

Appropriate diagnosis may constitute a challenge since these aneurysms are not easily distinguishable from tumours of the fourth ventricle and they are very rare.

Surgical occlusion was predominantly the main mode of treatment of these lesions due to relative accessibility. However, recent advancements in endovascular techniques and technology meant that progressively, more and more of these lesions are being treated through endovascularly. Our patient had endovascular coil embolization and occlusion from tonsillomedullary segment and she made good recovery.

\section{Conclusion}

Distal PICA aneurysms are extremely rare entities and they can present acutely with radiological features that closely mimic intraventricular tumours. It is imperative to have a high index of suspicion in order to carefully examine the imaging presented. A misstep in diagnosis and management could have potential high morbidity and/or mortality for the patient.

\section{References}

1. Hudgins RJ, Day AL, Quisling RG, Rhoton AL Jr, Sypert GW, et al. (1983) Aneurysms of the posterior inferior cerebellar artery. A clinical and anatomical analysis. J Neurosurg 58: 381-387.

2. Mabuchi S, Kamiyama H, Abe H (1992) Distal aneurysms of the superior cerebellar artery and posterior inferior cerebellar artery feeding an associated arteriovenous malformation: Case report. Neurosurgery 30: 284-287.
3. Lewis SB, Chang DJ, Peace DA, Lafrentz PJ, Day AL (2002) Distal posterior inferior cerebellar artery aneurysms: Clinical features and management. J Neurosurg 97: 756766.

4. Dannenbaum MJ, Du R, Day AL (2011) Surgical management of posterior circulation aneurysms. In: JP Mohrer, et al., Stroke. ( $5^{\text {th }}$ edn), WB Saunders, 1322-1335.

5. Lister RJ, Rhoton AL, Matsushima T, Peace DA (1982) Microsurgical anatomy of the posterior inferior cerebellar artery. Neurosurgery 10: 170-199.

6. Greenberg MS (2016) Handbook of neurosurgery. ( $8^{\text {th }}$ edn).

7. Horiuchi T, Tanaka Y, Hongo K, Nitta J, Kusano $\mathrm{Y}$, et al. (2003) Characteristics of distal posteroinferior cerebellar artery aneurysms. Neurosurgery 53: 589-595.

8. Rhim JK, Sheen SH, Oh SH, Noh JS, Chung BS (2005) Aneurysm of the posterior inferior cerebellar artery : Clinical features and surgical results. J Korean Neurosurg Soc 37: 399-404.

9. Park J-S, Lee T-H, Seo E-K, Cho Y-J (2008) Aneurysms of distal posterior inferior cerebellar artery. J Korean Neurosurg Soc 44: 205-210.

10. Tokimura H, Yamahata H, Kamezawa T, Tajitsu K, Nagayama T, et al. (2011) Clinical presentation and treatment of distal posterior inferior cerebellar artery aneurysms. Neurosurg Rev 34: 57-67.

11. Osborne A (2013) Osborn's brain: Imaging, pathology and anatomy. ( $1^{\text {st }}$ edn $), 500-514$.

12. Anegawa S, Hayashi T, Torigoe R, Nakagawa S, Furukawa $Y$, et al. (2001) Aneurysms of the distal posterior inferior cerebellar artery-analysis of 14 aneurysms in 13 cases. No Shinkei Geka 29: 121-129.

13. Sanusi TD, McLarnon M, Abouharb A (2020) Risk factors of chronic shunt dependent hydrocephalus following aneurysmal subarachnoid haemorrhage. Clinical Neurology and Neurosurgery 198: 106095. 